\title{
Hechos básicos sobre la inmigración en Tenerife
}

Elaborado por Dirk Godenau y Daniel BuraschI

Junio de 2018

Los movimientos migratorios y la presencia de personas inmigradas en nuestras sociedades están en el centro de la atención política y mediática en Europa. En un contexto en el cual los partidos xenófobos han aumentado de forma preocupante su base de apoyo y donde los rumores y las noticias falsas o tendenciosas están sesgando el debate público sobre las migraciones, es particularmente urgente e importante que la sociedad civil, las instituciones y los medios de comunicación cuenten con información fundamentada y contrastada. Promover y difundir el conocimiento científico de los fenómenos migratorios es una de las principales vocaciones del Observatorio de la Inmigración de Tenerife.

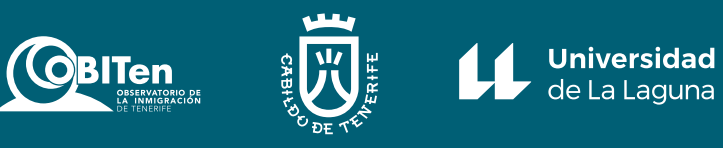




\section{¿Cuántos son?}

La población inmigrante se puede delimitar en las estadísticas disponibles utilizando diferentes criterios: la nacionalidad (extranjeros vs nacionales), el lugar de nacimiento (alóctonos vs autóctonos), o la movilidad transfronteriza (flujo de personas que entran en el país). Los primeros dos se miden para la población residente a través del Padrón de Habitantes y los Censos de Población. En cambio, la medición de los flujos migratorios emplea altas y bajas de los registros poblacionales o registros de los cruces de frontera, sean regulares o irregulares. Más allá de los criterios estadísticos, cabe añadir que en la vida cotidiana de la población inmigrante asimismo juegan un papel relevante otros factores como el fenotipo (los rasgos físicos), el accento, la forma de vestirse, las costumbres, etc., que también operan para que una persona sea identificada por las demás como "no de aquí", con independencia de su lugar de origen o nacionalidad.

La población que vive en Tenerife alcanzó a principios de 2017 la cifra de 895 mil personas (Tabla 1), de las cuales, 177 mil, el 19,8\%, había nacido en el extranjero, y 104 mil, el 11,6\%, tenían nacionalidad extranjera. La diferencia, de casi 74 mil personas, se debe principalmente a las nacionalizaciones de personas inmigrantes durante su asentamiento en España y la inmigración de personas de nacionalidad española nacidas en el exterior, fenómenos ambos que se dan con mayor frecuencia entre las personas de origen americano. Ello se refleja en que la población nacida en países americanos supone el 10 \% de la población de Tenerife, pero sólo el 3 \% cuando se limita a las correspondientes nacionalidades.

Tabla 1

Personas residentes en Tenerife según lugar de nacimiento, nacionalidad y origen en 2017 y variación con respecto a 2000 .

Fuente

ISTAC. Padrón de Habitantes, a 1 de enero del año.

\begin{tabular}{|c|c|c|c|c|c|c|c|}
\hline \multirow[b]{2}{*}{ Origen } & \multicolumn{3}{|c|}{ Según lugar de nacimiento } & \multicolumn{3}{|c|}{ Según nacionalidad } & \multirow{2}{*}{$\begin{array}{c}\text { Ratio } \\
\text { alóctonos / } \\
\text { extranjeros } \\
\text { (\%) }\end{array}$} \\
\hline & Población & $\%$ & $\begin{array}{l}\text { Var (\%) } \\
2000-17\end{array}$ & Población & $\%$ & $\begin{array}{l}\operatorname{Var}(\%) \\
2000-17\end{array}$ & \\
\hline Total & 894.636 & 100,0 & 26,1 & 894.636 & 100,0 & 26,1 & \\
\hline Extranjero & 177.456 & 19,8 & 233,0 & 103.703 & 11,6 & 231,7 & 171 \\
\hline $\begin{array}{l}\text { Resto de } \\
\text { UE-28 }\end{array}$ & 64.075 & 7,2 & 163,7 & 59.635 & 6,7 & 192,9 & 107 \\
\hline $\begin{array}{l}\text { Resto de } \\
\text { Europa }\end{array}$ & 6.173 & 0,7 & 450,7 & 5.243 & 0,6 & 602,8 & 118 \\
\hline África & 10.104 & 1,1 & 261,8 & 6.808 & 0,8 & 388,4 & 148 \\
\hline América & 87.999 & 9,8 & 294,7 & 25.681 & 2,9 & 280,3 & 343 \\
\hline Asia & 8.972 & 1,0 & 233,3 & 6.287 & 0,7 & 216,7 & 143 \\
\hline Oceanía & 133 & 0,0 & 38,5 & 49 & 0,0 & 69,0 & 271 \\
\hline
\end{tabular}

\section{¿Dónde están?}

A principios de 2017, Tenerife alberga el $42 \%$ de la población residente en Canarias. Su cuota en la población extranjera regional alcanza el 45 \% y el 47 \% en la población de origen extranjero. Si se atiende a la evolución de la población inmigrante en las diferentes islas (Gráfico 1), se observa que Tenerife comparte con todas las demás un fuerte crecimiento de esta población durante el boom económico entre los años 2000 y 2007, segui- 
do por un estancamiento durante la posterior crisis. El porcentaje que alcanza la población nacida en el extranjero en Tenerife está en un nivel claramente inferior al registrado en Fuerteventura y Lanzarote, pero también sustancialmente superior al de Gran Canaria.

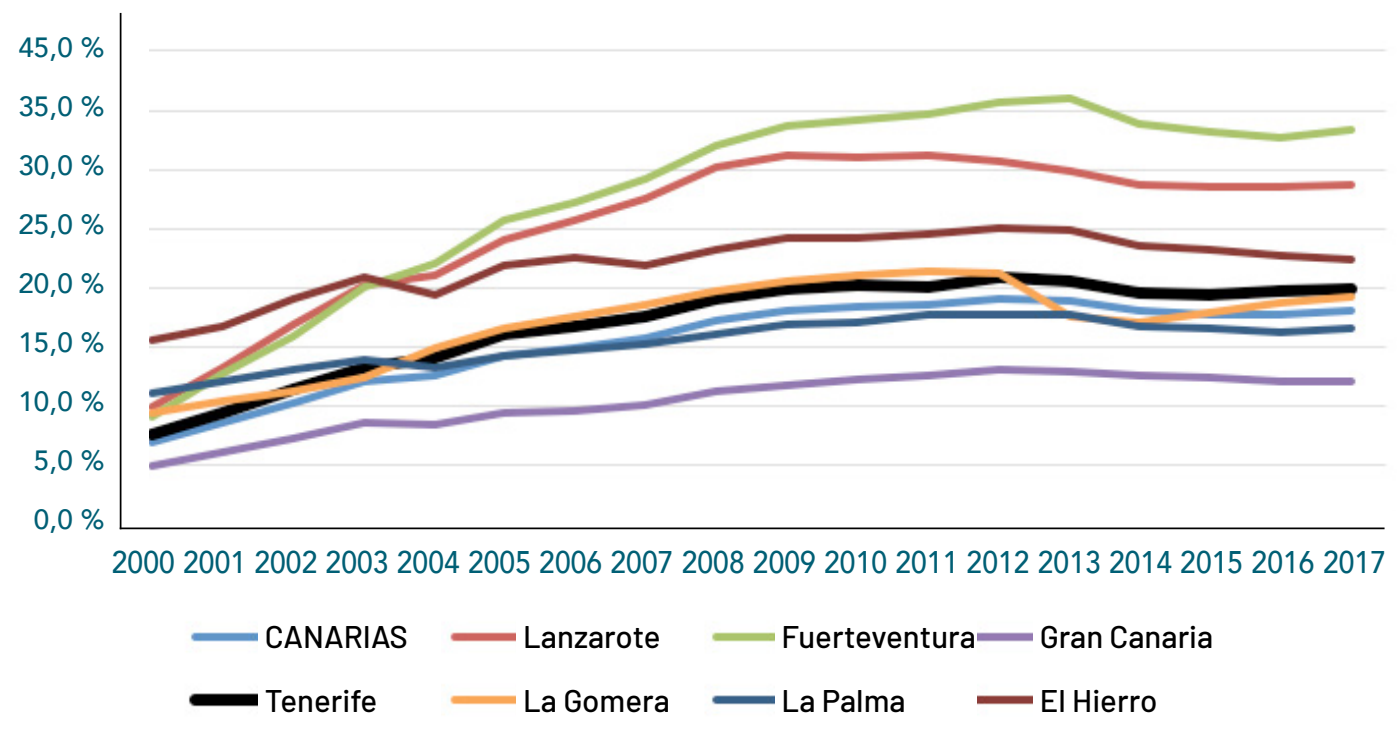

La distribución territorial de la población inmigrante en Tenerife (Mapa 1) refleja la importancia de la especialización económica y residencial de algunas áreas. Es en los municipios turísticos (Adeje, Arona, Santiago del Teide, Granadilla de Abona, Guía de Isora, San Miguel de Abona, Puerto de la Cruz) donde el porcentaje de población oriunda de otros lugares es mayor. En cambio, en los municipios más rurales estos porcentajes son frecuentemente inferiores al $10 \%$. Debido a los distintos tamaños y pesos poblacionales de los municipios en el conjunto de Tenerife, la distribución territorial del número absoluto de personas alóctonas sigue un patrón relativamente concentrado: el 70 \% de esta población vive en solo 5 de los 31 municipios de Tenerife: Santa Cruz de Tenerife, San Cristóbal de La Laguna, Arona, Adeje y Granadilla de Abona.

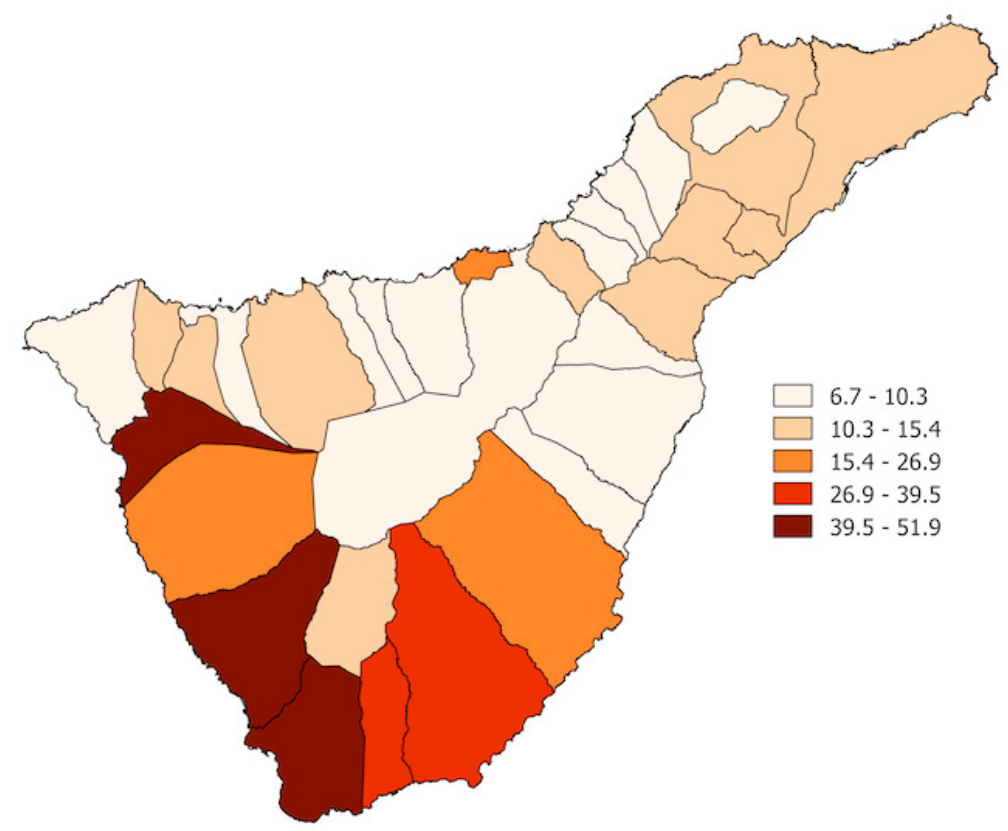

\section{Gráfico 1}

Evolución del porcentaje de la población nacida en el extranjero según isla entre 1997 y 2017

\section{Fuente}

ISTAC. Padrón de Habitantes, a 1 de enero del año.

Mapa 1

Municipios de Tenerife con porcentaje de población nacida en el extranjero a 1 de enero de 2017.

\section{Fuente}

ISTAC. Padrón de Habitantes. 


\section{¿De dónde son?}

La población tinerfeña está compuesta por personas de un amplio abanico de orígenes y nacionalidades: la población nacida en el extranjero procede de 170 países diferentes. Las procedencias más frecuentes (Tabla 2) son países americanos (Venezuela, Cuba, Argentina, Colombia) y europeos (Italia, Reino Unido, Alemania). En el décimo lugar del ranking de orígenes aparece el primer país africano: Marruecos. Los vínculos migratorios históricos entre Canarias y Cuba, y con Venezuela después, se manifiestan en el amplio porcentaje de personas nacidos en estos países que tienen nacionalidad española. A su vez, son las poblaciones de Venezuela e Italia las que han experimentado un fuerte crecimiento en fechas recientes.

Tabla 2

Ranking de los primeros

10 países y áreas de

origen o nacionalidad de la población residente inmigrante en Tenerife en 2017

Fuente

ISTAC. Padrón de Habitantes, a 1 de enero del año.

\begin{tabular}{|c|c|c|c|c|c|c|}
\hline \multirow[b]{2}{*}{ Rango } & \multicolumn{3}{|c|}{ Población nacida en el extranjero } & \multicolumn{3}{|c|}{ Población de nacionalidad extranjera } \\
\hline & País & Población & $\begin{array}{l}\operatorname{Var}(\%) \\
2000-17\end{array}$ & País & Población & $\begin{array}{l}\operatorname{Var}(\%) \\
2000-17\end{array}$ \\
\hline $1^{\circ}$ & Venezuela & 38.223 & 163,2 & Italia & 17.311 & 814,0 \\
\hline $2^{\circ}$ & Italia & 17.540 & 738,8 & Reino Unido & 11.793 & 74,7 \\
\hline $3^{\circ}$ & Cuba & 16.637 & 490,6 & Alemania & 8.639 & 30,8 \\
\hline $4^{\circ}$ & Reino Unido & 12.826 & 66,0 & Venezuela & 7.676 & 166,0 \\
\hline $5^{\circ}$ & Alemania & 9.758 & 24,5 & $\begin{array}{l}\text { Ampliación UE } \\
\text { de } 2004\end{array}$ & 6.130 & $2.648,9$ \\
\hline $6^{\circ}$ & Argentina & 8.001 & 392,1 & Cuba & 4.383 & 229,1 \\
\hline $7^{\circ}$ & $\begin{array}{l}\text { Otros países } \\
\text { de América }\end{array}$ & 7.796 & 425,0 & $\begin{array}{l}\text { Otros países } \\
\text { de Europa }\end{array}$ & 4.380 & $1.215,3$ \\
\hline $8^{\circ}$ & Colombia & 7.775 & $1.406,8$ & Rumanía & 3.566 & $4.994,3$ \\
\hline $9^{\circ}$ & $\begin{array}{l}\text { Ampliación UE } \\
\text { de } 2004\end{array}$ & 6.240 & $2.202,6$ & Argentina & 3.547 & 358,3 \\
\hline $10^{\circ}$ & Marruecos & 5.428 & 219,9 & $\begin{array}{l}\text { Otros países } \\
\text { de América }\end{array}$ & 3.418 & 312,8 \\
\hline
\end{tabular}

\section{¿Qué perfil tienen?}

La estructura por edad y sexo de la población inmigrante en Tenerife no es sustancialmente distinta de la pirámide de población española que reside en la isla (Gráfico 2); en ambos casos es elevado el peso que tienen las edades centrales. Las diferencias se limitan a un grado de envejecimiento algo menor en la población extranjera y, al mismo tiempo, una menor presencia de personas menores de edad.

No obstante, esta situación general es el resultado de una superposición de estructuras por edad y sexo claramente diferenciadas entre los distintos orígenes de la población inmigrante. Debido a la motivación laboral de gran parte de las inmigraciones desde países no europeos durante el crecimiento económico, esta población llegó a Canarias en edades relativamente jóvenes. En cambio, en la inmigración europea hay una parte amplia de personas de edad avanzada que acuden a Tenerife por motivos residenciales y no participan en el mercado de trabajo. 

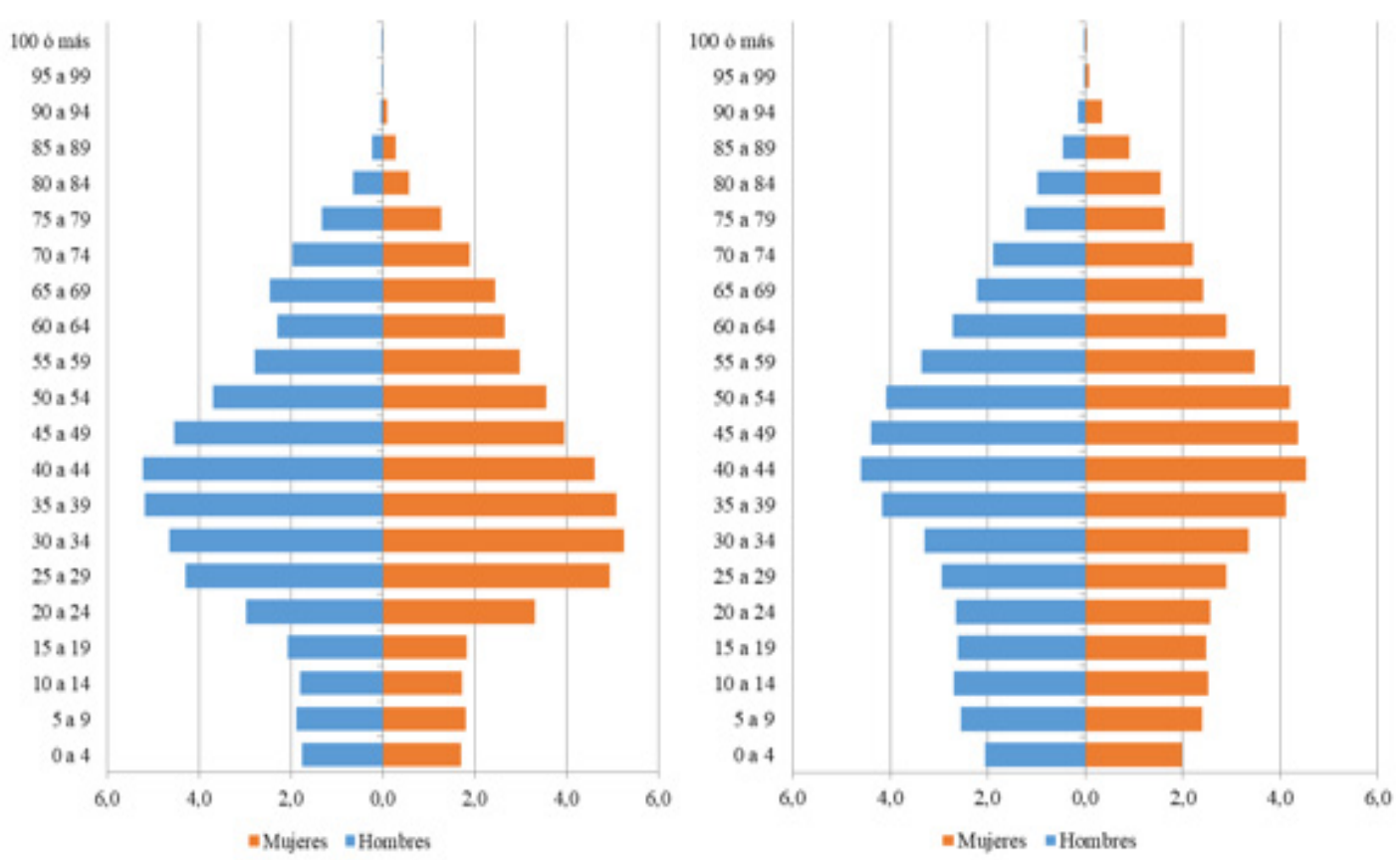

\section{Gráfico 2}

Población según edad y sexo residente en Tenerife a 1 de enero de 2017 (en tantos por mil)

(panel izquierdo con población extranjera, panel derecho con población española)

\section{Fuente}

ISTAC. Padrón de Habitantes

\section{¿Cómo han venido?}

Pasando ahora de las características de la población inmigrada a los flujos migratorios, es decir, las personas que entran y salen de la isla de Tenerife, las altas (inmigraciones) y las bajas (emigraciones) en el Padrón de Habitantes permiten una aproximación a los saldos migratorios exteriores (Gráfico 3).

Durante el periodo 2002-2016 se observan tres etapas distintas. La primera, hasta el año 2007 y en un contexto de crecimiento económico, cuenta con saldo migratorio elevado (inmigración neta); la segunda, desde 2008 a 2015, registra como efecto de la crisis una fuerte reducción de este saldo hasta valores incluso moderadamente negativos en 2015; y la tercera etapa, iniciada en 2016, refleja las consecuencias de la recuperación económica en mayores niveles de inmigración y una reducción de las emigraciones (Domínguez y Díaz; incluido en Godenau y Buraschi, 2017b).

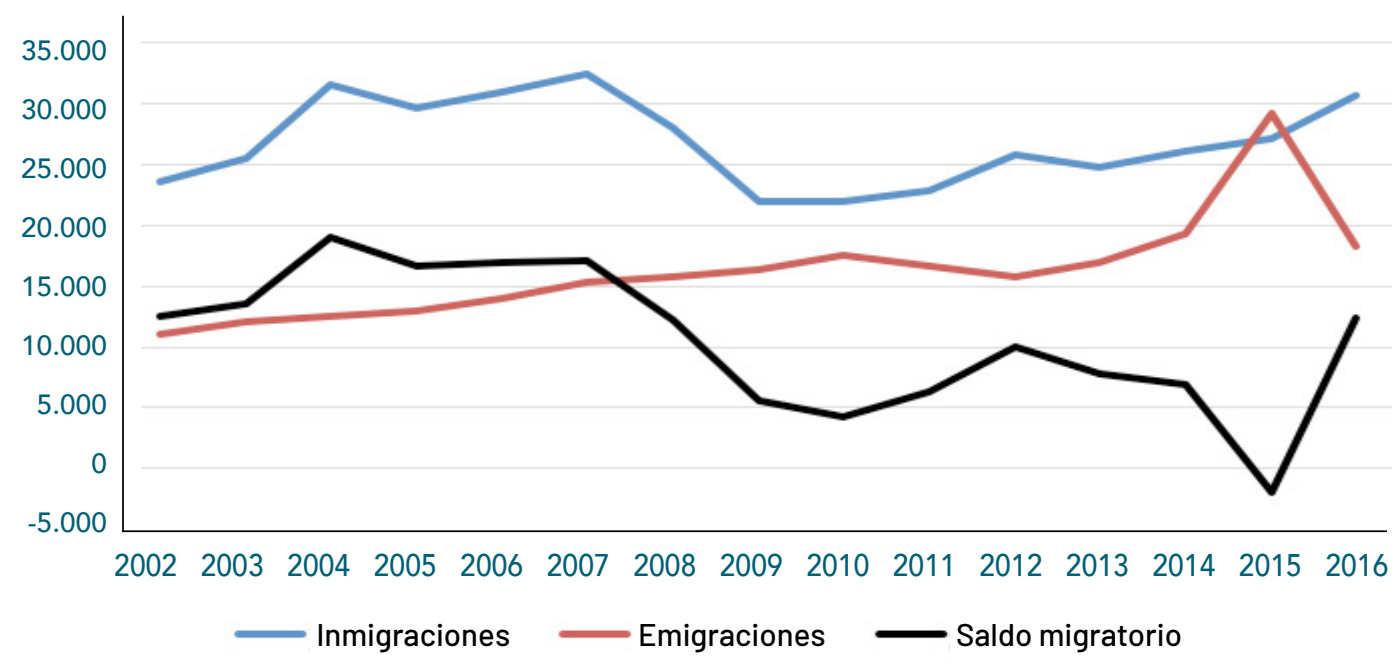

\section{Gráfico 3}

Evolución de los movimientos migratorios exteriores de Tenerife entre 2002 y 2016

(incluye Otras islas, Resto de España y Extranjero; tanto como orígenes como destinos)

\section{Fuente}

ISTAC. Estadística de Variaciones Residenciales. 
Los flujos migratorios pueden calificarse desde la administración como regulares o irregulares. En el caso de las migraciones irregulares conviene diferenciar entre el cruce irregular de la frontera (ejemplo, llegadas marítimas en pateras o cayucos) y la estancia en el país sin los correspondientes permisos. Las personas que cruzan la frontera irregularmente no se quedan necesariamente en el lugar de arribada, porque es posible que transiten hacia otros territorios, o que, en caso de ser interceptados, sean derivados hacia otros lugares por parte de las autoridades. A su vez, la entrada en el país puede ser regular (ejemplo, como turista vía aeropuertos), pero con una posterior irregularidad "sobrevenida", al carecer de los preceptivos permisos de residencia.

Como parte de la ruta atlántica de la emigración africana hacia Europa, Canarias es el lugar de llegada de personas que se embarcan en la costa occidental del continente vecino para acceder a la Unión Europea. Durante los años 2002 a 2008, estas arribadas fueron mucho más cuantiosas que en fechas anteriores y posteriores (Gráfico 4), alcanzando un pico destacado en 2006 durante la denominada "crisis de los cayucos". Actualmente este flujo se encuentra en niveles más bajos y la reactivación de la ruta atlántica dependerá de los acontecimientos en las rutas oriental y occidental del Mediterráneo, ahora de mayor permeabilidad relativa. En 2017 han llegado desde las costas de África 418 personas en 16 embarcaciones. Se trata de un número muy reducido con respecto al año 2006 cuando se registraron 31.678 personas. El perfil de las personas que llegaron por esta vía en 2017 está compuesto por hombres adultos $(87,7 \%)$, menores de edad $(8,7 \%)$ y mujeres (3,5 \%). La mayoría de las embarcaciones sale de Marruecos o del Sáhara Occidental, pero algunas también emprenden su periplo desde Senegal y Gambia (CEAR, 2017). Los datos preliminares de 2018 indican una intensificación incipiente de esta afluencia.

Personas detenic

Gráfico 4 que han llegado a Canarias a bordo de embarcaciones por lugares no habilitados entre 1994 y 2017.

Fuente

Ministerio del Interior y prensa especializada.

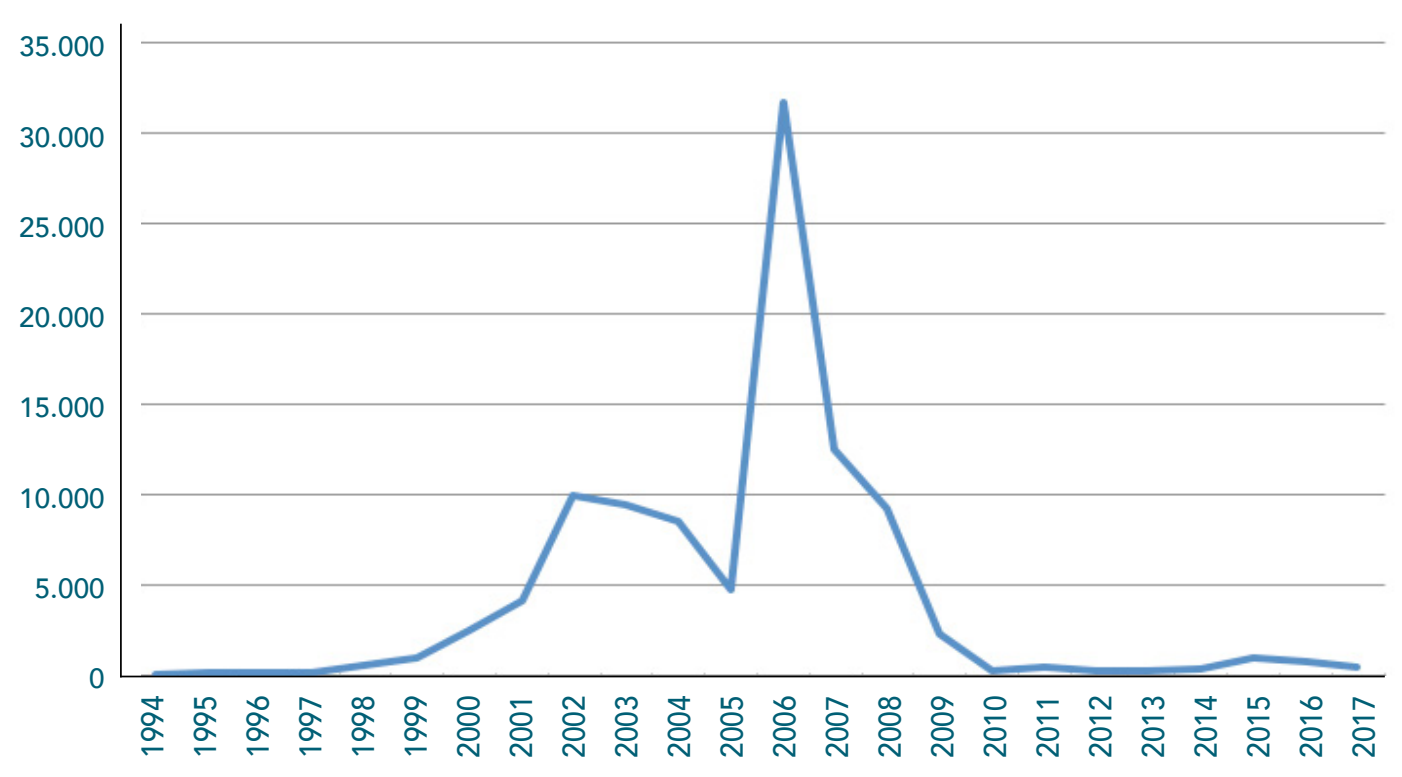

El reducido nivel de la inmigración marítima irregular hacia Canarias implica, entre otros aspectos, la menor incidencia de las peticiones de asilo en territorio canario. No obstante, la presencia y atención de refugiados no se limita, en principio, a las personas que recalan en busca de refugio al Archipiélago, porque también pueden llegar a través de las derivaciones desde otros territorios. En Canarias, a lo largo de 2017, se han registrado 820 peticiones de asilo; la mayoría de solicitudes es de personas procedentes de Venezuela, Sáhara Occidental y Ucrania. 


\section{¿Cuál es su situación?}

Las personas inmigrantes que viven en Tenerife no sólo son diversas por sus orígenes, también lo son en muchos otros aspectos, como por su posición económica y social en la sociedad tinerfeña. En este sentido, conviene huir de los estereotipos que pretenden reducir esta diversidad a simplificaciones centradas en los extremos, tanto el de la pobreza como el otro de la opulencia.

Hecha esta advertencia, parece procedente prestar especial atención a las dificultades que experimenta una parte no menor de la población inmigrante. Según el estudio realizado para el Observatorio Permanente de la Inmigración en España, sobre las distintas dimensiones de la integración de los inmigrantes en las regiones españolas (Godenau et al., 2017), muchas personas residentes en el Archipielago, sean inmigrantes o no, sufren niveles salariales bajos, elevadas tasas de paro y precariedad laboral. De las regiones españolas, Canarias es la que menores diferencias registra entre extranjeros y nacionales, pero en este aparente éxito de integración incide la también desfavorable situación de los nacionales (convergencia a la baja). Las desventajas laborales de la población inmigrante se hacen particularmente visibles en el problema de la sobrecualificación, indicativo de que una parte de las personas migrantes no logra poner en valor su formación en el mercado de trabajo local. La crisis ha agravado estos problemas (Godenau y Buraschi, 2017a).

Esta situación laboral es el condicionante principal de las dificultades a las que parte de la población (inmigrante) se enfrenta para conseguir los ingresos necesarios para el bienestar material de sus familias. Los correspondientes indicadores de desigualdad y pobreza (Padrón Marrero; incluido en Godenau y Buraschi, 2017b) muestran que la población inmigrada suele tener menores ingresos y rentas que los nacidos en Canarias. Es en los indicadores de relaciones sociales y ciudadanía donde la situación es mucho más favorable, porque el paso del tiempo ha permitido mejoras sustanciales en la regularidad documental y las competencias lingüísticas.

Hay que recordar que las personas inmigradas no representan un grupo homogéneo: sus condiciones de vida en Canarias varían mucho según los países de origen, diferencias que están especialmente relacionadas con su situación laboral, los ingresos del hogar, la estructura familiar y los años de residencia en España. Las personas de origen africano son el colectivo que más ha sufrido los efectos de la crisis económica. Según la encuesta realizada por OBITen (Godenau y Buraschi, 2017a) el 52,6\% de los inmigrantes africanos ha tenido que disminuir los gastos de alimentación a causa de la crisis, frente al 11,0\% de los inmigrantes de la Unión Europea. Con respecto a la estructura familiar, las personas migrantes que viven en hogares unipersonales (compuestos por solo una persona) y monoparentales (una persona adulta con hijos/as a cargo) son las que llegan a final de mes con mayores dificultades. 


\section{¿Qué pasará?}

Las perspectivas de evolución de la inmigración en Tenerife están condicionadas fundamentalmente por la coyuntura económica. Una vez superada la crisis económica e iniciada la recuperación de la creación de empleo, es probable que la emigración siga reduciéndose y que se prolongue la reactivación de la inmigración. De hecho, la población regional ha experimentado un incremento del 1,03\% entre 2017 y 2018, sumando alrededor de 20 mil nuevos habitantes, derivado sobre todo del saldo migratorio exterior positivo, ascenso porcentual de escala regional solo superado por las Islas Baleares y la Comunidad de Madrid. En el contexto del envejecimiento de la población europea, ello contribuirá a la renovación y diversificación de la población tinerfeña y canaria, una vitalidad demográfica que es un elemento clave del futuro éxito económico y social.

Para ampliar la información:

CEAR (2017), Refugiados y migrantes en España: Los muros invisibles tras la frontera sur, Madrid, Comisión Española de Ayuda al Refugiado. [disponible en https://www.cear.es]

Godenau, D. y Buraschi, D. (2017a), Movilidad y condiciones de vida de los inmigrantes durante la crisis económica en Tenerife, Cabildo de Tenerife, Área de Empleo, Comercio, Industria y Desarrollo Socioeconómico, Santa Cruz de Tenerife. [disponible en www.obiten.net]

Godenau y Buraschi (eds.) (2017b), Migraciones, desigualdad e integración en tiempos de crisis. Cabildo Insular de Tenerife, Área de Empleo, Comercio, Industria y Desarrollo Socioeconómico, Santa Cruz de Tenerife. [disponible en www.obiten.net]

Godenau, D., Rinken, S., Martínez de Lizarrondo Artola, A., Moreno Márquez, G. (2017), La integración de los inmigrantes en España: fases, patrones y dinámicas regionales durante el periodo 2007-2015, Ministerio de Empleo y Seguridad Social, Madrid. [disponible en http:// extranjeros.empleo.gob.es]

\section{Cómo citar este artículo:}

Godenau, D. y Buraschi, D. (2018). Hechos básicos sobre la inmigración en Tenerife. OBITen Factsheet 1-2018. Recuperado de www.obiten.net

El Observatorio de la Inmigración de Tenerife es una iniciativa conjunta del Cabildo de Tenerife y la Universidad de La Laguna que surge con vocación de estructura permanente y dinámica para avanzar en el conocimiento científico de los movimientos migratorios. OBITen desarrolla su actividad a modo de centro de recopilación, producción y difusión de información que facilita la opinión cualificada y favorece la toma de decisiones que redunden en una mejor gestión del fenómeno inmigratorio y sus implicaciones.

http://www.obiten.net 